Popa V. I. ${ }^{1,3}$, Lascar I. ${ }^{1,2}$, Valcu M. ${ }^{1,2}$, Ioana Teona Sebe ${ }^{1,2}$, Caraban B. ${ }^{4,}$ Arina Cristiana Margina ${ }^{5}$

\title{
Bioethics in animal experimentation
}

\author{
${ }^{1}$ Plastic Surgery and Reconstructive Microsurgery Department, Clinical Emergency Hospital, Bucharest \\ 2 "Carol Davila" University of Medicine and Pharmacy, Bucharest \\ ${ }^{3} \mathrm{PhD}$ candidate, "Carol Davila" University of Medicine and Pharmacy, Bucharest, \\ ${ }^{4}$ Faculty of medicine, University "Ovidius" Constanţa \\ ${ }^{5}$ Plastic Surgery and Reconstructive Microsurgery Departament, Emergency Hospital "Prof. Dr. Agrippa \\ Ionescu", Bucharest
}

\begin{abstract}
Animal experiments are used on a large scale worldwide in order to develop or to refine new medicines, medicinal products or surgical procedures. It is morally wrong to cause animals to suffer, this is why animal experimentation causes serious moral problems.

We must realize that we have moral and legal obligations when dealing with animals in our care, and this should become our high priority before any experiment. We have to take responsibility for the life of the animals and we have to act honorably regarding this issue because we have been given a trust by society in general which is not to be taken lightly.

There is an ongoing societal debate about ethical issues of animal use in science. This paper is addressed to current and future researchers and is an appeal for them to (re)consider their personal views concerning the issue under scrutiny and their responsibility in ensuring that results would make the sacrifice worthwhile.
\end{abstract}

Keywords: animal experimentation, bioethics, legislation, 3Rs, animal welfare

\section{Popa Victor Ioan}

Clinical Emergency Hospital, Bucharest

email: victorioanpopa@gmail.com

\section{Introduction}

Animal experimentation has become a complex issue in modern society. Millions of animals are used every day in extremely painful procedures in order to develop or to refine new medicines, medicinal products or surgical techniques.

Legislation to regulate the use of animals for scientific experiments dates back to the Cruelty to Animals Act established in the UK in 1876 [1]. Nowadays, the 3 Rs concept (replacement, reduction, refinement) reflects the efforts both in research and in legislation to set parameters for the animal use in science. The final regulations that incorporate the most common principles for the protection of laboratory animals are: the 3 Rs must be applied whenever possible; experiments must be indispensable; pain, suffering, and death must be justifiable; the entire process must be regulated by controlling and authorizing systems.

Despite all this and the fact that medical science has gained valuable knowledge from animal experiments, animal experimentation has become a cruel reality in the today's world [1]. In the 15 "old" EU Member States alone, in the year 2003, about 10 
million vertebrate animals were used for scientific and other experimental purposes according to the latest official statistics [2]. It must be assumed that the real number is considerably higher, as serious shortcomings have been reported regarding these statistics $[3,4]$. The reason why animal numbers are gradually rising again is that whole new areas of research have opened up for which there are not viable alternatives yet and the most common example is genetic engineering. This is because it is not yet possible to manipulate genes in vitro and then study the effect in whole living systems. So, whilst molecular biology can shed light on structures and interactions of genes and proteins, integrative studies using animals are key in translating information from the genome into advances in understanding human and animal disease and in developing the next generation of new medicines [5].

In the light of this reality, many animal welfare organizations have decided to participate in any effort that could contribute to diminishing the suffering of animals in the laboratories. This should not be misunderstood as giving up the vision of abolishing all animal experiments but rather taken as a first resort measure [1].

This review, therefore, aims to introduce its readers to important issues which have arisen out of the animal experimentation debate that will assist them in making well thought out decisions before proceeding with an animal experiment. Not many of us are fully conversant with the origins of modern animal experimentation practices, and fewer still with the intricacies of the philosophical debate about the moral status of animals [6]. In Western countries, animal experimentation is governed by legislation that aims to ensure that animals are used in ways in which suffering is minimized [6].

Moreover, the purpose of this review is to highlight the main problems that constitute this modern debate about animal experimentation so that any future scientist, doctor, or medical student that becomes actively involved with animal experiments will be able to justify to themselves and to others any intrusive procedure involving certain sentient animals and to make a personal decision about the extent to which they are prepared to use research animals [6].

\section{Definition and characteristics of animal experi- ments}

The terms animal testing, animal experimentation, animal research, in vivo testing and vivisection have similar denotations, but different connotations. Generally, they would be understood as any experimental procedure carried out on an organism from the zoological (taxonomic) category Animalia. However, in existing legislation, reference is made mostly to vertebrate animals, based on the assumption that only vertebrates would have the capacity to feel pain and to suffer [1]. Whereas there is no scientifically accepted rationale for that assumption, in the last decades, overwhelming scientific evidence has been collected to demonstrate that a number of non-vertebrate species possess a well-developed nervous system that makes them capable of suffering in a way that we would assume for most vertebrates $[7,8]$. This evidence has resulted in increased attention to certain species, as can be demonstrated by the fact that the octopus had been included into the UK legislation on the protection of laboratory animals [9].

The term "vivisection" literally means the "cutting up" of a living animal and has a negative connotation, implying torture, suffering and death. The word is preferred by those opposed to the research, whereas scientists typically use the term "animal experimentation".

The major areas where animal experimentation is used are: basic and applied (biomedical) research; regulatory testing of drugs, compounds and products; regulatory (routine) testing of biological substances and products; educational purposes [1].

The animal species used in experiments range from non-sentient Protozoa to Great Apes. The most common laboratory animal species are rats and mice. Almost all animal species that are kept as pets are also used in research and testing, like hamsters, guineapigs, cats, and dogs [1]. Primates are also widely used in many areas, and are imported from breeding colonies in third-world countries where they are often bred under questionable conditions. Also, a lot of 
research is carried out on the so-called farm animals (pigs, cows, horses, and poultry) [1].

\section{Historical remarks and attitudes regarding animal experimentation}

It is worthwhile to mention the historical course of vivisections in order to understand how public concern and social attitudes arose.

Live animals, both human and non-human, appear to have been first used in ancient times, principally to satisfy anatomical curiosity [6]. In the third century $\mathrm{BC}$, the Alexandrian physicians Herophilus and Erasistratus are recorded to have examined functional differences between sensory nerves, motor nerves, and tendons [6]. Galen of Pergamum (AD 129-199) described for the first time the cardiopulmonary system and investigated the characteristics of the nervous system. Because all these procedures were made under no anesthesia, which was not discovered until the mid-nineteenth century, Galen wrote that he preferred to vivisect pigs over apes so that he could not see their expression on their faces when investigating the anatomy of the brain [10].

St. Thomas Aquinas (1225-74) had declared in his Summa Theologiae (1260) that humans were unique; all other animals were incapable of rationality because they possessed no mind. Only humans had a soul and the power to reason. Without a soul, animals were merely objects, devoid of personality or rights. They existed only for human needs and were bereft of moral status [11].

The Belgian Andreas Vesalius (1514-64) and his students in Padua, Italy, illustrated public lectures on anatomy by using systematic non-human vivisection. An animal, usually a dog, would be cut open while still alive and the function of each organ would be speculated upon as it was located. It appears, from the records of these procedures, that the welfare of their experimental subjects was a low priority for these early vivisectionists. [10]
The seventeenth century was marked by an intense scientific activity. Philosopher René Descartes (1596-1650) played an important role in early debates over vivisection. Descartes stated that it was possible to describe humans and other animals as complex machine bodies that would obey known laws of mechanics. Descartes also believed, however, that the divine gift of the soul distinguished the human animal from all others. Humans were conscious and capable of rational thought, humans were capable of acts of free will, and had true language. Only humans could declare "Cogito ergo sum" and not the animals [6]. Thus, the ideology of vivisectionists was that animals could not suffer pain because they did not have a soul or consciousness.

The rate of animal experimentation increased into the seventeenth and into the eighteenth and nineteenth centuries. Claude Bernard (1813-1878) wrote during his procedures that it is better to use animals for testing his ideas because he believed that the results would be conclusive for humans.

Animal experimentation continued; the number of animals used in experiments increased and more medical breakthroughs occurred at the beginning of the twentieth century, further emphasizing the value of using animals in biomedical research. These included the extraction of the first hormone (1902), a chemical treatment for syphilis (1909), and the isolation, by Banting and Best (1920), of insulin, leading to the development of an effective treatment of diabetes mellitus $[6,12]$.

In 1989, the American Medical Association's Council on Scientific Affairs published an impressive list of medical advances made possible through research using animals. It included studies of anesthesia, autoimmune deficiency syndrome (AIDS), and autoimmune diseases, behavior, cardiovascular disease, cholera, diabetes, gastrointestinal surgery, genetics, hemophilia, hepatitis, infant health, infections, malaria, muscular dystrophy, nutrition, ophthalmology, organ transplantation, Parkinson's disease, prevention of rabies, radiobiology, reproductive biology, shock, the skeletal system, treatment of spinal injuries, toxoplasmosis, yellow fever, and virology [6].

From this point of view, how can we not see the benefits that came from sacrificing so many animals? 
This is the major argument that scientists offer when animal experiments are questioned.

On the other hand, it has elsewhere been estimated that $95 \%$ of drugs found safe and effective in nonhuman animal tests are rejected as harmful or useless during human clinical trials [13]. In one 25year study, 40,000 species of plants were tested for anti-tumor activity on animals by the United States National Cancer Institute. Of those substances found safe and effective on nonhuman animals, not one usable and safe agent survived human tests [14]. The sleeping agent, thalidomide, caused 10,000 human babies to be born with flippers instead of arms [15]. Tuberkulin cures tuberculosis in guinea pigs but causes it in humans. The arthritis medicine, Oraflex, was safe and effective on animals but kills humans, and indeed guinea pigs can safely eat strychnine, while sheep can consume large quantities of arsenic [15]. Digitalis, a cardiac drug that has saved millions of human lives, was delayed in its release because it dangerously elevates blood pressure in dogs [15] The discoverers of penicillin are grateful that no guinea pigs were available for testing, for it kills these small animals [15]. Morphine causes mania in cats and mice, and dogs have twenty times the tolerance for it that humans do [15]. Cases such as these abound. Nonhuman animals make very poor models for predicting results for human beings and that is supposed to be the whole point of animal experimentation [15].

\section{Opposition to animal experimentation}

Opposition to the use of animals for research purposes is not an entirely modern phenomenon. The first people who started to think vivisections are cruel were some professional physiologists [6]. Only later did the general public become passionately involved. Professional opposition was based on a moral objection to cruelty, because as we mentioned before, efficient anaesthesia was not available until midnineteenth century [6]. They started questioning the value of the results obtained from killing animals, but still they considered their actions would bring benefits for humanity. After all, the early public opposition was not based on a perception of cruelty, but rather on the argument that because of the fundamental differences (both anatomical and spiritual) believed to separate humans from other animals, little relevant benefit could be derived from experimentation on "lesser" beings. Information gained from non-human vivisection could not legitimately be extrapolated to the human form [6].

It was the nineteenth century that brought a revolutionary change on the perception of animal experimentation. The Society for the Prevention of Cruelty to Animals (SPCA) had been inaugurated in 1824 and its members committed themselves to the principles of kindness to animals, educating the general public about cruelty, and to lobbying parliamentarians for the enactment of anti-cruelty legislation [6]. The SPCA received the patronage of Princess Victoria in 1835 and in 1840, as Queen Victoria, she gave permission for the society to use the 'Royal' prefix [6]. Following the publication of evidence of the anesthetic properties of ether in 1847, the RSPCA opposed all painful vivisection. Throughout the nineteenth century, the RSPCA lobbied successfully for numerous changes to legislation [6,17].

In June 1874, Queen Victoria expressed her concern over the treatment of animals used in experiments, and guidelines had already been published in 1871 that aimed to minimize suffering and discourage conducting experiments which were of dubious scientific merit $[18,19]$.

All these were happening after the publication of Charles Darwin's On the Origin of Species by Natural Selection. Darwin had provoked furious debate with his theory that human beings and nonhuman beings had a common ancestor [6]. Such an idea was unbelievable for the contemporary Christian theology, undermining arguments that all non-humans were a gift from God, to be used by humanity to their own ends. One such end was, of course, scientific curiosity - but, if we were related to the animals, the question was how we could use them in experiments perceived as cruel [6].

In 1876, the Cruelty to Animals Act was 
passed and it required that any person wishing to perform experiments using live vertebrates must first be licensed, and all experiments involving cats, dogs, horses, mules, and asses, or those conducted to illustrate lectures, be certified by the British Home Secretary [6].

Major Charles W. Hume (1886-1981) formed in 1926 the University of London Animal Welfare Society (later to become the Universities Federation for Animal Welfare, UFAW). The society was able to publish the UFAW Handbook on the Care and Management of Laboratory Animals in 1947 [6,20]. Furthermore, William Russell and Rex Burch described The Principles of Humane Experimental Technique (1959), a guide which introduced the notion of the 'three Rs', meaning: to seek replacements for animal experiments whenever possible; a reduction in the number of animals used in each procedure; and the refinement of experiments to eliminate unnecessary procedures.

In the USA, medical research flourished in the twentieth century and that is why the lack of concerted opposition to animal experimentation delayed federal animal protection legislation until the 1960s and left scientists free to perform certain experiments that could not be conducted elsewhere. The attempts of anti-vivisectionist societies had gone largely unheard by the American public, because discoveries such as that of a diphtheria antitoxin in 1894 were announcing promises of health and wealth [6]. Therefore, the number of animal used in experiments increased, including pets, and the discoveries of experimental psychology and the work of physiologists like Ivan Pavlov were being published.

In 1952, an organization called the Animal Welfare Institute (AWI), was set up by Christine Stevens to fight for the rights of the unwanted pets. The 1970s and 1980s marked an increased interest in the welfare of animals (the Animal Welfare Act in 1985) even among philosophers such as Peter Singer in his work Animal Liberation [6].

We should note that Peter Singer is a selflabelled animal liberationist, but remains a classic case of utilitarianism. Utilitarianism is a theory in normative ethics holding that the moral action is the one that maximizes utility. Singer says that we should equally favour equivalent interests, no matter the species of the interest holder, and always promote those consequences that are best overall. However, Singer assumes that since we would not treat humans with limited mental abilities cruelly, or without equally considering their suffering, so we must never be tempted to treat animals (who are said to have limited cognitive abilities) cruelly or with disregard either [15].

Although the author of Animal Liberation does not advocate liberating all animals from experimentation, Singer is highly critical of callousness towards suffering, and of experiments that do not seem useful, promising or repetitive [15]. An important condition of Singer's argument is that if human subjects who have the mental capacities of nonhuman animals are available, and since they would be more suitable for medical research concerning humans and the results more valid, they too should be used for experiments [21]. And that is how the living will clause has arisen:

The Living Will Argument

I, being a supporter of animal experiments who is of sound mind and body, do hereby consent to being utilized in biomedical research, as a 'special volunteer', WHEREAS my mental capacity, through accident, injury, or developmental problems, will have become equivalent to that of a nonhuman animal;

WHEREAS such research could be defended on grounds of possible benefits;

WHEREAS such research is comparable to such research now conducted on animals;

and

WHEREAS said research will be approved by the National Research Board.

In signing this document, I take no special notice of any heroism on my part, but am simply doing my expected duty, which any conscientious citizen rightly ought to undertake.

Date: Signature: [15]

The problem is the utilitarian who favors experimenting on animals but refuses to offer himself / herself for such research under the conditions stated is betraying their utilitarian principles [15]. The consensus today is that humans should not be used for invasive medical research because it is against the law. Not all humans are capable of giving consent and 
the same should be true in the case of animals. This also relates to the Kantian idea of universalizability: we should be willing to suffer what we propose to do to others. People who are prepared boldly to sacrifice animals will not be so brave when they find themselves subject to the same fate. So the question is 'Would you volunteer instead of the animals?' [15]

\section{Ethical principles and regulations on animal research}

As we mentioned before, the legislation to regulate the use of animals for scientific purposes dates back to the Cruelty to Animals Act that was established in the UK as early as $1876[1,9]$. In many countries, animal welfare legislation was enacted in the 19th or 20th centuries, and sometimes it also covered animal experimentation [1].

For example, the UK Animals (Scientific Procedures) Act (1986) is administered through the British Home Office that produces publicly available annual reports that detail aspects of experimentation conducted under the Act $[6,22]$. The UK Act offers strict protection for all living vertebrates as well as for the common octopus, Octopus vulgaris. It controls animal research in the following ways: certification and licensing of researchers and their projects; institutional certification; enforcement through the Home Office inspectorate; the establishment of an Animal Procedures Committee. Researchers and other responsible individuals who breach the UK Act are guilty of criminal offences $[6,23]$.

The USA model differs from the British and Australasian systems in that certain vertebrates are currently excluded from protection under government legislation (the Federal Animal Welfare Act) [6]. Following amendment in 1971, the Act now specifically excludes: “. . . birds, rats of the genus Rattus and mice of the genus Mus bred for use in research, and horses not used for research purposes and other farm animals, [. . .], used or intended for use as food or fiber for improving animal nutrition, breeding, management, or production efficiency, or for improving the quality of food or fiber " $[6,24]$.

To conclude, from an animal welfare point of view, the above mentioned regulations have proved to be of limited efficiency as is demonstrated by the reality of animal experimentation today, which still allows for performing animal experiments for even the most absurd purposes. On the other hand, at least in theory, the present regulations are meant to incorporate the most common principles for the protection of laboratory animals:

- experiments must be indispensable for specified purposes;

- pain, suffering or distress must be ethically justifiable;

- the 3Rs must be applied wherever possible;

- animal experiments, as well as the breeding and housing of laboratory animals have to be practically regulated by controlling and authorizing systems [1].

\section{The solution: alternatives to animal experimen- tation}

Criticism of animal experimentation remains a much debatable issue that seems to have no solution. The only answer comes from William Russell and Rex Burch in their publication, The Principles of Humane Experimental Technique (1959), emphasizing the need for scientists to appraise their work based on the principle of the 'three Rs'. They recommended that research efforts be directed towards the ultimate replacement of sentient animals in experiments with non-sentient or non-living alternatives at every opportunity [6]. This is the ideal towards any researcher should strive.

In the absence of complete replacement, scientists must reduce the number of experiments so that only those considered essential will be performed. The number of animals used in such procedures should also be reduced as much as possible and also, scientists should refine experiments to minimise or 
eliminate completely any suffering involved [6]. These recommendations have been accepted universally as a cornerstone of modern research practices [6,25].

\section{Conclusions}

This review has the main purpose to present the need for moral considerations in all experiments which involve animals. Despite exhaustive attempts to define a single ethical model for animal experimentation, none has proved comprehensive. The problem when trying to assess whether an animal experiment is justifiable or not is that there is not a minimum standard for purposes that would be regarded as ethical or unethical. History shows that there has been a societal controversy over this issue, but this does not mean that such an ethic goal cannot be achieved. The 'three Rs' of William Russell and Rex Burch represent a solid foundation to construct an ethical standard regarding animal experimentation and that is by introducing alternatives at every opportunity, reducing the numbers of animals involved in essential experiments, and refining procedures to minimize or eliminate suffering.

We think that excluding by law all animal experiments is something that cannot be achieved by democratic means in the short term and, for that, legislation must be improved drastically.

The only valid and present solution for this ethical problem which includes the lives of the animals presents itself as a scientific approach and that would be replacing all animal use in science and research by alternative methods. This would be the future: designing scientific studies that aim to replace animals in research experiments and all efforts should be concentrated in this direction.

This paper has also been written to help a researcher form his own ideas over animal experimentation before proceeding with such a form of experiment. Some may be drastic over this issue, but most of the researchers will choose the middle path and will use animals in their research only when necessary.

We must realize that we have moral and legal obligations when dealing with animals in our care, and this should become our high priority before any experiment. We have to take responsibility for the life of the animals and we have to act honorably regarding this subject because we have been given a trust by society in general which is not to be taken lightly.

In the end, our advice for future researchers is to think twice before performing any kind of procedure on an animal and to have in mind some basic principles and to consider why animals are being used (isn't there another solution?), to consider the requirements for animal welfare and animal handling, to consider personal views in using animals and to consider the responsibility to ensure that the result would overcome the sacrifice.

\section{Acknowledgement:}

This paper is supported by the Sectoral Operational Programme Human Resources Development (SOP HRD) financed from the European Social Fund and by the Romanian Government under the contract number POSDRU/159/1.5/S/137390

\section{References}

1. Kolar, R., (2006), Animal experimentation, Science and Engineering Ethics, Volume 12 issue 1 2006, doi 10.1007\%2Fs11948-006-0011-,1

2. ***. (2005). Commission of the European Communities (2005) Fourth report from the Commission to the Council and the European Parliament on the statistics on the number of animals used for experimental and other scientific purposes in the member states of the 
European Union. COM(2005) 7 final, Brussels, 20.01.2005. http://www.europa.eu.int/comm/ environment/chemicals/lab_animals/pdf/ com_2005 7 en.pdf Retrieved 17.02.2015

3. Sauer U.G., Spielmann H. \& Rusche B. (2005). Fourth EU Report on the statistics on the number of animals used for scientific purposes in 2002 trends, problems, conclusions. ALTEX 22: 19-24

4. Sauer U.G. \& Kolar R. (2000). Developments in the collection of statistical information on the number of animals used in experiments and other scientific purposes in the European Union. ATLA 28: $133-145$

5. British Pharmacological Society. Integrative Pharmacology Fund. Imperial College London Centre for Integrative Mammalian Physiology and Pharmacology.

6. Monamy V. (2009). Animal Experimentation. $A$ Guide to the Issues. Cambridge: Cambridge University Press.

7. Mather J.A. (2001). Animal suffering: An invertebrate perspective. Journal of Applied Animal Welfare Science 4, 151-156.

8. Sherwin C.M. (2001). Can invertebrates suffer? Or, how robust is argument-by-analogy?. Animal Welfare 10, 103-118.

9. Anon. (1986). Animals (Scientific Procedures) Act 1986. UK Home Office. http://www. homeoffice.gov.uk/docs/animallegislation.html. Retrieved 17.02.2015

10. Maehle A.-H. \& Troehler, U. (1987). Animal experimentation from antiquity to the end of the eighteenth century: attitudes and arguments. Rupke, N.A. (ed.), Vivisection in Historical Perspective, 14-47. London: Croom Helm.

11. Linzey, A. \& Clarke, P.A.B. (2004). Animal Rights: A Historical Anthology. Irvington, NY: Columbia University Press.

12. Bliss, M. (1982). The Discovery of Insulin. Chicago, IL: University of Chicago Press.

13. Sharpe, R. (1988). The Cruel Deception: The Use of Animals in Medical Research Wellingborough, Northamptonshire: Thorsons Publishers Limited, p. 90. F. I. McMahon, Medical World News 168, 6 (1968) cited in Ibid., indicates that only one out of twenty drugs tested safe and effective on nonhuman animals are safe and effective for humans after clinical trials.

14. Sharpe, R. 1988. The Cruel Deception: The Use of Animals in Medical Research Wellingborough, Northamptonshire: Thorsons Publishers Limited, op. cit., p. 78, 105

15. Sztybel, D. (2006). A Living Will Clause for Supporters of Animal Experimentation. Journal of Applied Philosophy. 23(2). doi 10.1111\%2Fj.1468-5930.2006.00338.x.

16. Anon. (1986). Animals (Scientific Procedures) Act 1986. UK Home Office. http://www. homeoffice.gov.uk/docs/animallegislation.html. Retrieved 20.10.2014

17. French, R.D. (1975). Antivivisection and Medical Science in Victorian Society. Princeton, NJ: Princeton University Press.

18. Ryder, R.D. (2000). Animal Revolution: Changing Attitudes Towards Speciesism, second edition. Oxford: Berg Publishers.

19. Phillips, M.T. \& Sechzer, J.A. (1989). Animal Research and Ethical Conflict: An Analysis of the Scientific Literature 1966-1986. New York: Springer Verlag.

20. Poole, T. (ed.) (1999). UFAW Handbook on the Care and Management of Laboratory Animals, Vol. 1, Terrestrial Vertebrates. Oxford: Blackwell Science.

21. Pifer L., Shimizu K. \& Pifer R..(1994) Public attitudes toward animal research: some international comparisons. Society and Animals: Journal of Human-Animal Studies 2, 2. http:// www.psyeta.org, the website of Psychologists for the Ethical Treatment of Animals. Retrieved 20.10.2014

22. UK Home Office 2007. Statistics of Scientific Procedures on Living Animals, Great Britain 2006. London: The Stationery Office. http:// www.archive2.official-documents.co.uk/ document/cm62/6291/6291-old.pdf. Retrieved 20.10.2014

23. UK Home Office 2008a. Animals in Scientific Procedures: Better Regulation. http:// scienceandresearch.homeoffice.gov.uk/ animal-research/better-regulation/. Retrieved 20.10.2014

24. Hamm, T.E., Dell, R.B. \& Van Sluyters, R.C. (1995). Laboratory animal care policies 
and regulations: United States. Institute for Laboratory Animal Research Journal 37: 75-8.

25. FRAME Toxicity Committee (1991). Animals and alternatives in toxicology: present status and future prospects. Alternatives to Laboratory Animals 19: 116-38. 